\title{
Selection of nitrogen-fixing deficient Burkholderia vietnamiensis strains by cystic fibrosis patients: involvement of nif gene deletions and auxotrophic mutations
}

\author{
Aymeric Menard, ${ }^{1}$ Claire Monnez, ${ }^{1}$ \\ Paulina Estrada de los Santos, ${ }^{1 \dagger}$ Christine Segonds, ${ }^{2}$ \\ Jesus Caballero-Mellado, ${ }^{3}$ John J. LiPuma, ${ }^{4}$ \\ Gerard Chabanon ${ }^{2}$ and Benoit Cournoyer ${ }^{1 *}$ \\ ${ }^{1}$ Research group on «Bacterial Opportunistic Pathogens \\ and Environment», Université de Lyon, Lyon, F-69003, \\ France; Université Lyon 1, Villeurbanne, F-69622, \\ France; CNRS, UMR5557, Ecologie Microbienne, \\ Villeurbanne, F-69622; Ecole Nationale Vétérinaire de \\ Lyon, Marcy L'étoile, F-69280, France. \\ ${ }^{2}$ Observatoire cepacia, Laboratoire de Bacteriologie- \\ Hygiene, Institut Federatif de Biologie, Hôpital Purpan, \\ TSA 40031, 31059 Toulouse Cedex 9, France. \\ ${ }^{3}$ Centro de Ciencias Genómicas, Universidad Nacional \\ Autónoma de México, Ap. Postal 565-A, Cuernavaca, \\ Morelos, Mexico. \\ ${ }^{4}$ Department of Pediatrics and Communicable Diseases, \\ University of Michigan, Ann Arbor, MI 48109, USA.
}

\section{Summary}

Burkholderia vietnamiensis is the third most prevalent species of the Burkholderia cepacia complex (Bcc) found in cystic fibrosis (CF) patients. Its ability at fixing nitrogen makes it one of the main Bcc species showing strong filiations with environmental reservoirs. In this study, $83 \%$ (29 over 35 ) of the $B$. vietnamiensis CF isolates and $100 \%$ of the environmental ones (over 29) were found expressing the dinitrogenase complex (encoded by the nif cluster) which is essential in $\mathrm{N}_{2}$ fixation. Among the deficient strains, two were found growing with ammonium chloride suggesting that they were defective in $\mathrm{N}_{2}$ fixation, and four with amino acids supplements suggesting that they were harbouring auxotrophic mutations. To get insights about the genetic events that led to the emergence of the $\mathrm{N}_{2}$-fixing defective strains, a genetic analysis of $B$. vietnamiensis nitrogen-fixing property was undertaken. A 40-kb-long nif cluster and nif

Received 4 October, 2006; accepted 14 December, 2006. ${ }^{*}$ For correspondence. E-mail cournoye @ biomserv.univ-lyon1.fr; Tel. (+33) 4724314 95; Fax (+33) 4724312 23. 'Present address: Vrij Universiteit Brussel, Pleinlaan 2, B-1050, Brussel, Belgium. regulatory genes were identified within the $B$. vietnamiensis strain G4 genome sequence, and analysed. Transposon mutagenesis and nifH genetic marker exchanges showed the nif cluster and several other genes like glt $B$ (encoding a subunit of the glutamate synthase) to play a key role in $B$. vietnamiensis ability at growing in nitrogen-free media. nif cluster DNA probings of restricted genomic DNA blots showed a full deletion of the nif cluster for one of the $\mathrm{N}_{2}$-fixing defective strain while the other one showed a genetic organization similar to the one of the G4 strain. For $17 \%$ of $B$. vietnamiensis clinical strains, CF lungs appeared to have favoured the selection of mutations or deletions leading to $\mathrm{N}_{2}$-fixing deficiencies.

\section{Introduction}

The Burkholderia genus is part of the Betaproteobacteria and consists of more than 30 bacterial species. It includes a tight phylogenetic complex of more than 10 species which is named the Burkholderia cepacia complex (Bcc). Most of these Bcc species can infect cystic fibrosis (CF) patients. They can also infect immunocompromised individuals or patients with chronic granulomatous disease (for review of Bcc infections see Mahenthiralingam et al., 2005). Burkholderia vietnamiensis is the third most prevalent species of the Bcc found among CF patients (LiPuma, 2005). The most damaging and prevalent Bcc species in CF patients are B. cenocepacia and B. multivorans. Burkholderia vietnamiensis was also reported in bacteraemia (Magalhães et al., 2003) and a neck abscess (Gillis et al., 1995). Other Burkholderia species like B. gladioli and $B$. pseudomallei were also recorded in CF patients (Bauernfeind etal., 1998; O'Carroll et al., 2003). Burkholderia pseudomallei is the aetiological agent of melioidosis (Brygoo, 1953).

Several Burkholderia species including those of the Bcc are well known for their potential benefits in agriculture and the chemical industries. Burkholderia spp. can also be nitrogen fixers, converting $\mathrm{N}_{2}$ into $\mathrm{NH}_{3}$. Only one species of the Bcc, $B$. vietnamiensis, is, these days, considered able to fix nitrogen (Perin et al., 2006). However, the literature published prior to the definition of the Bcc 
and B. vietnamiensis grouped several diazotrophs into B. cepacia (Bevivino et al., 1994), leading to some confusion regarding the distribution of the $\mathrm{N}_{2}$-fixing property in the Bcc. Plant growth can be promoted by nitrogen fixation (e.g. Somers et al., 2004).

Diazotrophs like B. vietnamiensis produce a nitrogenase complex that can catalyse the reductive breakage of $\mathrm{N}_{2}$ into $\mathrm{NH}_{3}$. The nitrogenase complex is made up of two main components; a dinitrogenase and a dinitrogenase reductase. The first one is a heterotetramer with a molybdenum-iron cofactor, and is encoded by the nifD and nifK genes. The latter is a dimer encoded by nifH. The reduction of one molecule of $\mathrm{N}_{2}$ by the nitrogenase complex was shown to require at least 16 ATP (Dixon and Kahn, 2004). This is considered one of the most energydemanding reaction. In consequence, the synthesis of the nitrogenase complex is stringently regulated. Among the diazotrophs investigated thus far, several regulatory networks involved in $\mathrm{N}_{2}$ fixation have been described. In proteobacteria, NifA acts with the $\sigma^{54}$ transcriptional factor to regulate transcription of the nifHDK operon (Dixon and Kahn, 2004). nifA expression and activity of the NifA protein are regulated by several factors that can vary from one species to another. They mainly concern nitrogen availability, redox and oxygen. The nitrogenase complex is oxygen labile (for review see Dixon and Kahn, 2004). Genes involved in nitrogen fixation are mostly found in a single genomic region, named the nif cluster.

The ability of $B$. vietnamiensis at fixing nitrogen makes it one of the main Bcc species showing strong filiations with environmental reservoirs. Burkholderia vietnamiensis can thus be considered an excellent model to address the problems of community-acquired strains and their acclimation to the CF lung environment. Studying this Bcc species could also bring light into the understanding of the selective forces that drive the evolution of these bacteria in CF lungs, and that can lead to an emergence of more fit clonal complexes. However, there is so far no evidence of any particular genetic adaptation or drift among $B$. vietnamiensis suggesting an increased fitness for $C F$ lungs. In fact, nitrogen fixation is still considered a key character in the allocation of Bcc strains to the B. vietnamiensis group (Gillis et al., 1995), suggesting this property to be always conserved whatever the origin of the strain. Nevertheless, at the time of this latter study, despite the fact that some clinical isolates were analysed, no CF B. vietnamiensis isolate was available. In this work, we postulated that if more adapted $B$. vietnamiensis $\mathrm{CF}$ lung isolates were emerging, nitrogen fixation should be one of the main activities affected by the genetic processes involved. Secretions and sputum from CF lungs are rich in amino acids (Barth and Pitt, 1996; Thomas et al., 2000; von Bredow et al., 2001), and, in consequence, the nitrogenase complex should not be expressed and could be counter-selected. However, outside CF lungs, in soil and the rhizosphere, nitrogen sources being scarce, B. vietnamiensis isolates should have conserved their nitrogen-fixing ability. Here, we thus present an investigation of the nitrogen-fixing abilities of a large collection of $B$. vietnamiensis isolates coming from CF patients, non-CF clinical specimens, soil and the rhizosphere of various plants. This study shows a loss of nitrogen-fixing activity by several CF strains because of the deletion or mutation of nif genes or genes involved in amino acids biosynthesis. No environmental strain showed a loss of nitrogen-fixation activity. The $B$. vietnamiensis nif cluster is described for the first time in this paper.

\section{Results and discussion}

The genetics of nitrogen fixation in $\mathrm{B}$. vietnamiensis

The genetics of nitrogen fixation has never been investigated in Burkholderia vietnamiensis. Three analyses were thus performed prior to investigate the processes involved in the emergence of nitrogen-fixing deficient $B$. vietnamiensis: (i) an annotation of the genes of the B. vietnamiensis $\mathrm{G} 4$ draft genome sequence likely to be involved in nitrogen fixation, with inferences regarding their regulation, (ii) phylogenetic and syntheny analyses of the nif clusters among the Burkholderia genus, and (iii) the mutagenesis of some of the genes involved in nitrogen fixation. Figure $1 \mathrm{~A}$ presents the annotation of the B. vietnamiensis G4 genetic determinants involved in nitrogen fixation. The physical organization of these genes shows similarities with the one of other nitrogen fixers. Burkholderia vietnamiensis $\mathrm{G} 4$ contains a $40 \mathrm{~kb}$ nif cluster grouping more than 50 genes involved in the synthesis of the dinitrogenase complex and its genetic regulation. This cluster shows the classical nifHDK and nifENX genetic organizations. Syntheny with $B$. xenovorans nif cluster is conserved from position 1748546 to 1788938 on chromosome 2, with a single indel related to the presence of a putative iscS gene in the B. xenovorans nif cluster (Fig. $1 \mathrm{~A}$ and B). Outside the nifHDK and nifENX organizations, syntheny is poorly conserved with nif clusters of non-Burkholderial genomes; several rearrangements can be observed.

A nifA gene, encoding an enhancer binding protein, is encoded by the $B$. vietnamiensis strain G4 nif cluster. NifA is the main regulatory protein of the nif cluster, and it has a modular domain structure. Burkholderia vietnamiensis NifA shows three domains, GAF, a AAA+ ATPase, and a helix-turn-helix domain, which are involved in DNA binding and interaction with the $\sigma^{54}$ RNA polymerase holoenzyme. Our inferences about B. vietnamiensis G4 genes likely playing a role in nitrogen fixation suggest that 
A :

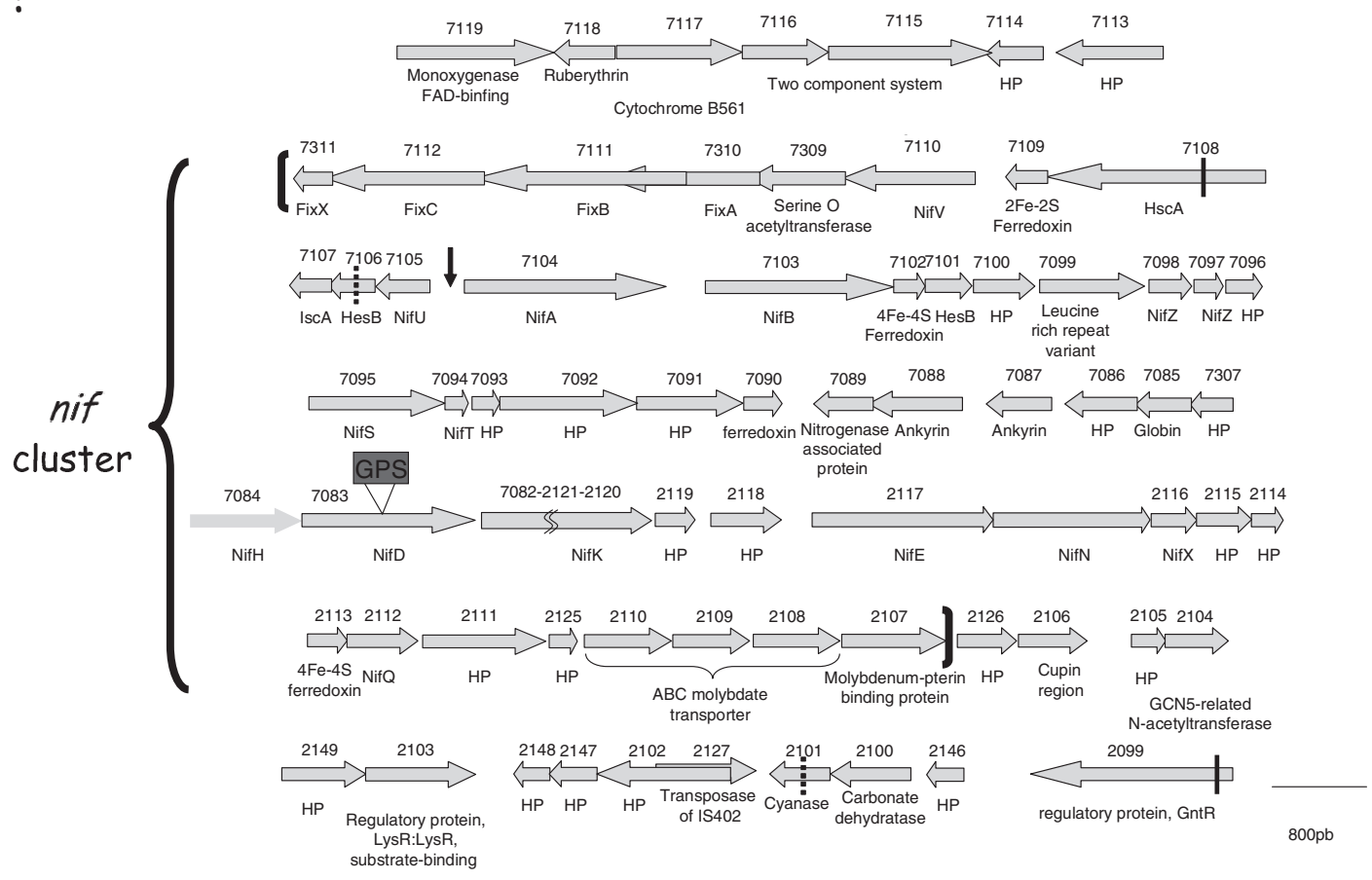

B :

C:

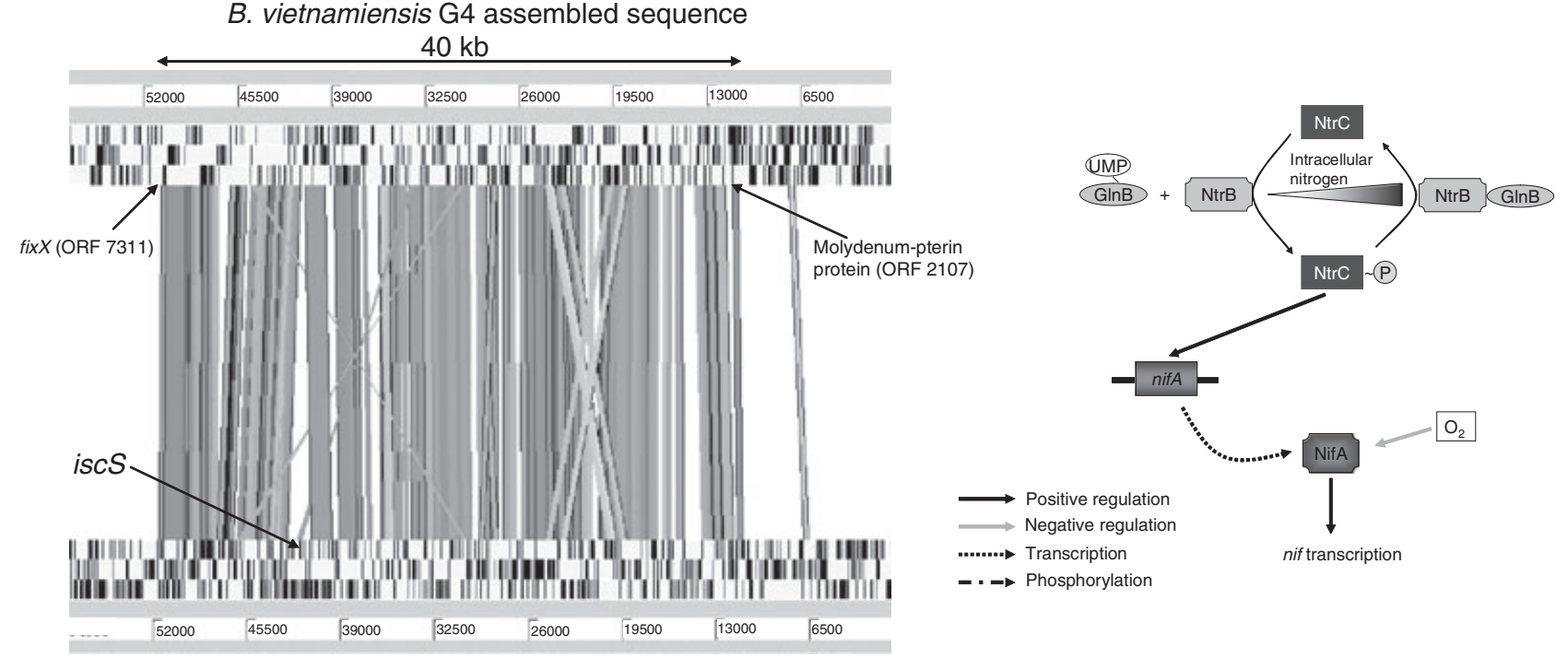

Part of $B$. xenovorans LB400 chromosome 2 sequence.

Fig. 1. Organization of the nitrogen-fixation genetic (nif) cluster of the B. vietnamiensis G4 genome.

A. ORFs and their putative deduced proteins of the $B$. vietnamiensis G4 nif cluster and its closest flanking sequences. The ORFs sequencing project annotation numbers are indicated. The GPS insertion site in nifD is indicated. A black arrow indicates the position of iscS found in B. xenovorans LB400 genome but not detected in the G4 genome. Vertical bars indicate borders of the L3E cosmid, while dotted bars indicate those of the L9C cosmid. Waved bars indicate a gap in the partially assembled B. vietnamiensis G4 genome release (26/01/2005 version). Brackets indicate nif cluster boundaries.

B. Graphic representation of the Artemis Comparison Tool (using TBLASTX) of the syntheny between nif clusters of B. vietnamiensis G4 (from ORF 2099 to 7119) and B. xenovorans LB400 chromosome 2 (accession \#NC_007952).

C. Inferred nif regulation cascade in $B$. vietnamiensis. 


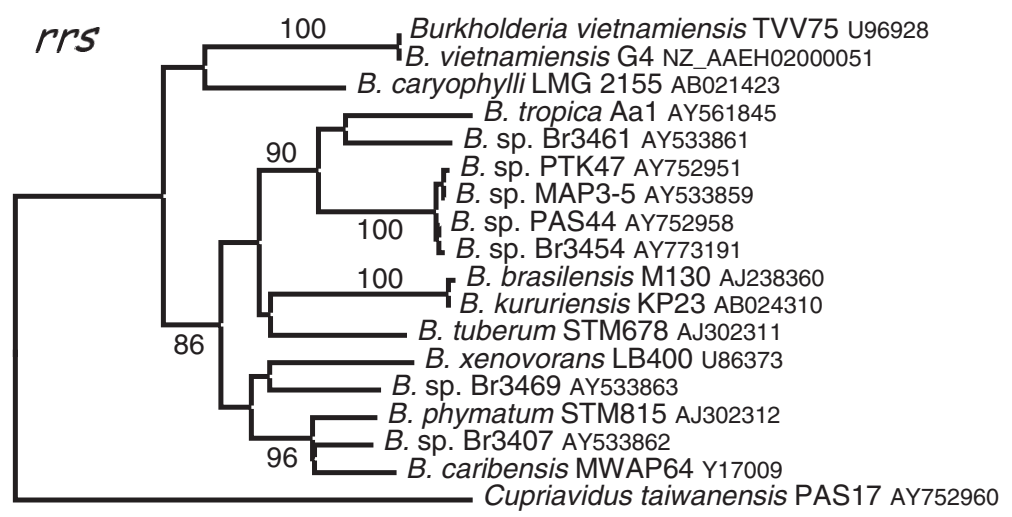

Fig. 2. Nitrogen-fixing Burkholderia species rrs (16S rDNA) and nifH Neighbour-Joining phylogenetic trees. The sequences were retrieved from the GenBank database or were obtained in this work. Distances are proportional to evolutionary divergences expressed in substitutions per 100 sites. Gap-containing sites were removed by pairs. Bootstrap values higher than $85 \%$ are given. Accession numbers of the sequences obtained in this work are as follow: DQ979867 (LMG 16232), DQ979868 (JC2.10), DQ979869 (AU1160), DQ979870 (AU0749), DQ979871 (AU0829) and DQ979872 (AU0913).

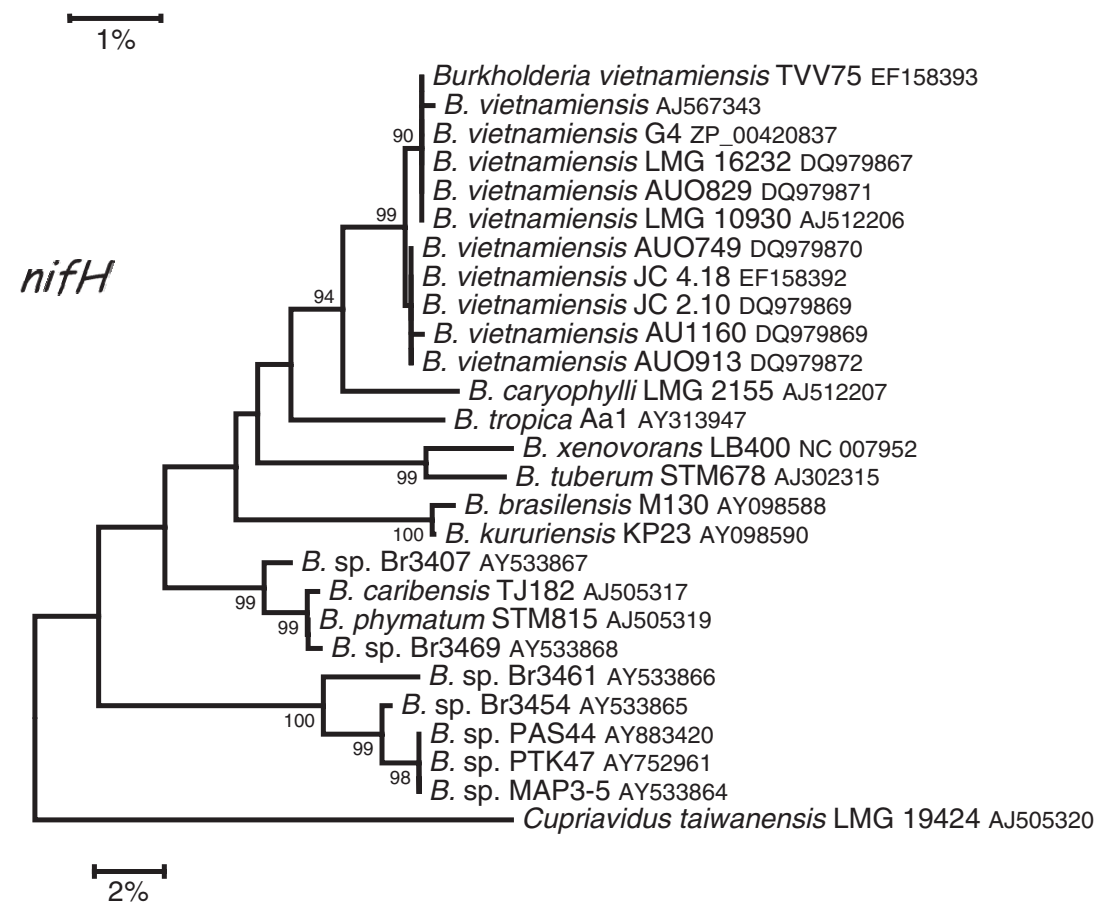

NifA activity would be directly responsive to oxygen, and would not involve a NifL oxygen sensor. In fact, no nifL encoding gene could be found in B. vietnamiensis G4. However, four PAS containing deduced proteins (oxygen sensors) were detected in B. vietnamiensis G4 including two histidine kinases (numbered ORFs 1771 and 4216) and two response regulators (numbered ORFs 5496 and 6748 ). One of these PAS containing proteins was found to be a NtrB orthologue. NtrB is part of a two-component system that senses the cell nitrogen status. Burkholderia vietnamiensis G4 NtrB is likely to play a role in nifA regulation of nitrogen fixation according to nitrogen availability but could also be involved in a regulatory process responding to both nitrogen and oxygen status. The gene encoding the response regulator interacting with NtrB, named ntrC (ORF 4215), was also found in B. vietnamiensis G4 genome. The glnB (named ORF 3159) and gInK (named ORF 4433) genes, producing PII signal-transduction proteins interacting, respectively, with $\mathrm{NtrB}$ and $\mathrm{AmtB}$ (involved in nitrogen transport) in function of the nitrogen status of the cell, were also found in the $B$. vietnamiensis G4 genome. PII proteins are uridylylated in the absence of nitrogen. Uridylylated GInB-PII proteins cannot interact with $\mathrm{NtrB}$, which can then phosphorylate the NtrC response regulator that will favour nifA expression and nitrogen fixation (see Dixon and Kahn, 2004). The $n t r B C$ and $g / n B K$ genes were not found at a close physical proximity of the nif cluster. An inferred regulatory cascade of $B$. vietnamiensis G4 nif transcription is shown in Fig. 1C.

A comparative phylogenetic analysis of the nifH nitrogenase complex structural gene with the one of the rrs gene encoding the 16S rRNA among the Burkholderia genus was performed and showed some discrepancies between the inferred phylogenetic trees (Fig. 2). Two main differences are the position of the B. tropica and 
B. xenovorans sequences. In the rrs tree, the B. tropica sequence is closely related to a group of sequences from unspecified strains (supported by $90 \%$ of the bootstrap replicates) but, in the nifH tree, its sequence is more closely related to $B$. vietnamiensis and B. caryophylli sequences. In the nifH tree, the B.xenovorans LB400 sequence is grouping with the one of $B$. tuberum (99\% of the bootstrap replicates) but, in the rrs tree, sequences from these two species are not closely associated. It thus appears that the nif cluster could be transferred laterally from one species to another. It is noteworthy that the nif cluster is found in about $25 \%$ of the Burkholderia species.

To confirm the involvement of the nif cluster in B. vietnamiensis nitrogen-fixation activity, a library of 1000 Tn-insertional mutants of strain TVV75 ${ }^{\top}$ was built. These insertional mutants were overlaid onto nitrogen-free medium. Eight mutants showed reduced or no growth on nitrogen-free medium. ARA (acetylene reduction activity) test showed three (named 4B8, 7E4 and 9D8) of these not to have a nitrogenase activity, and five (named $5 \mathrm{C} 11$, $5 \mathrm{G} 1,2 \mathrm{E} 10,1 \mathrm{E} 4$ and 9E5) to have a reduced activity likely due to a much decreased doubling time. The Tn-containing genomic region of each mutant showing no nitrogenase activity was rescued and cloned into Escherichia coli S17 $\lambda$ pir. The Tn-insertion region was sequenced. The mutant 4B8 had an insertion in the gltB gene (matching position 1051 of the cds encoding the GltB of ZP_00426623) encoding the large subunit of the dimeric glutamate synthase (GOGAT) protein. This enzyme is part of the ammonium assimilation pathway involving glutamine synthase. Depending on the bacterial species considered, the assimilation of nitrogen sources by GOGAT mutants appeared variable (Bani et al., 1980; Mandal and Ghosh, 1993). Here, the B. vietnamiensis GOGAT mutant (named 4B8) was found to grow onto nitrogen-free medium supplemented with $0.5 \%$ glutamate or $0.5 \%$ glutamine but not $5 \mathrm{mM} \mathrm{NH}_{4} \mathrm{Cl}$, confirming the role of this enzyme in the assimilation of either ammonium derived from fixed and non-fixed nitrogen sources. The second mutant (named 9D8) was found to have an insertion in a permease gene (matching position 1422 of the cds encoding the permease of ZP_00420273), and the third one (named 7E4) had an insertion in a $\mathrm{rrl}$ gene encoding the 23S rRNA (matching position 1908 of B. vietnamiensis G4 rrl). Growth of these mutants was tested on minimal medium supplemented with $\mathrm{NH}_{4} \mathrm{Cl}$. These two mutants could not grow with this supplement suggesting that they were more likely affected in pathways involved in amino acids biosynthesis than nitrogen fixation. No mutant containing an insertion in the nif cluster was obtained.

To obtain a nif mutant, a genetic marker exchange strategy was finally used. A B. vietnamiensis cosmid library was built, and two nif-containing cosmid clones (named L3E and L9C) were selected. DNA sequencing of the cosmid inserts' ends was performed and allowed to position the inserts on the map of $B$. vietnamiensis $G 4$ genome (Fig. 1A). In vitro Tn-mutagenesis was performed on cosmid L3E, and a nifD insertional mutant was selected by PCR screenings and DNA probings (see Experimental procedures). A $6 \mathrm{~kb}$ Scal fragment of the mutagenized cosmid clone was subcloned into the pBluescript vector. This new construct was used to select Kn-r gene cassette exchanges into three B. vietnamiensis strains (LMG 6998, LMG 10823 and $C L)$ nifD gene sequences. The selected mutants were shown not growing onto semisolid nitrogenfree medium and not having any nitrogenase activity detectable by ARA. The B. vietnamiensis strain LMG6998nifD mutant was used for further analysis. This mutant was found growing onto semisolid nitrogen-free medium supplemented with $\mathrm{NH}_{4} \mathrm{Cl}$ (Table 1). These results clearly demonstrated the role of the nif cluster in $B$. vietnamiensis nitrogen-fixation activity. However, the data obtained through the analysis of the library of insertional mutants also showed that several other genes are essential in the assimilation of fixed nitrogen, and that several genetic events could thus explain a loss of nitrogen-fixation activity. However, the natural occurrence of nitrogen-fixation deficient strains among free-living nitrogen fixers had thus far not been documented.

\section{Loss of nitrogen-fixation activity and nif genes by B. vietnamiensis from CF patients}

A panel of 66 B. vietnamiensis strains was selected for this study (Table 2). This panel included 35 clinical strains from North American and French CF patients, and two strains from non-CF patients. All the other strains were environmental isolates coming mainly from the rhizosphere of plants like rice and teosinte (the wild relative of maize) but some soil and wastewater isolates were also included. The taxonomic status of all these strains was confirmed by the recA PCR-RFLP analysis elaborated by Mahenthiralingam and colleagues (2002). The 66 strains used in this work were selected from a larger collection of strains in which some clones were found identical by Spel pulsed field gel electrophoresis (PFGE) genotypings. Spel PFGE analyses showed a very important genetic diversity among our panel of strains. All Spel PFGE profiles showed more than seven band differences. The ARA assay was used to detect expression of the nitrogenase complex under nitrogen-free conditions. After 10 days of incubation at $28^{\circ} \mathrm{C}$, four growth phenotypes on semisolid nitrogen-free medium were observed for the 66 strains tested (Fig. 3): (i) bacterial growth just below the top of the agar, (ii) growth inside the agar at a depth of more than $2 \mathrm{~mm}$, (iii) diffused growth inside the agar at a depth of more than $2 \mathrm{~mm}$, and (iv) no growth. Sixty out of 66 
Table 1. Growth of $B$. vietnamiensis strains in semisolid defined medium.

Nitrogen-free medium supplemented with

\begin{tabular}{|c|c|c|c|c|c|c|c|c|c|c|c|c|c|}
\hline \multirow[b]{4}{*}{ Strain } & \multirow[b]{4}{*}{$\begin{array}{l}\text { LB (tryptone } \\
\text { yeast extract) }\end{array}$} & \multirow[b]{4}{*}{$\begin{array}{l}\text { Nitrogen-free } \\
\text { medium }\end{array}$} & & & & & & & & & & & \\
\hline & & & \multicolumn{8}{|c|}{ One amino acid } & \multirow{2}{*}{\multicolumn{3}{|c|}{$\frac{\text { Pair of amino acids }}{\text { Ser }}$}} \\
\hline & & & \multirow[b]{2}{*}{$\mathrm{NH}_{4}^{+}$} & \multirow[b]{2}{*}{ His } & \multirow[b]{2}{*}{ Tyr } & \multirow[b]{2}{*}{ Ser } & \multirow[b]{2}{*}{ Asp } & \multirow[b]{2}{*}{ Glu } & \multirow[b]{2}{*}{ Gln } & \multirow[b]{2}{*}{ Met } & & & \\
\hline & & & & & & & & & & & Glu & Gln & Asp \\
\hline TVV75 & + & + & + & + & + & + & + & + & + & nd & nd & nd & nd \\
\hline TVV75 gltB::Tn5 & + & - & - & nd & nd & nd & nd & + & + & nd & nd & nd & nd \\
\hline LMG 6998 nifD::Tn7 & + & - & + & + & + & + & + & + & + & nd & nd & nd & nd \\
\hline $\mathrm{CH}-\mathrm{D}(\Delta n i f)$ & + & - & + & + & + & + & + & + & + & nd & nd & nd & nd \\
\hline AU0913 & + & - & + & + & + & + & + & + & + & + & nd & nd & nd \\
\hline JC 4.18 & + & - & - & - & + & - & - & - & - & - & nd & nd & nd \\
\hline JC 2.10 & + & - & - & - & - & - & - & - & - & - & + & + & + \\
\hline AU0749 & + & - & - & - & - & - & - & - & - & + & - & - & - \\
\hline AU1160 & + & - & - & - & - & - & - & - & - & + & - & - & - \\
\hline
\end{tabular}

Nitrogen-free medium was supplemented with either $5 \mathrm{mM} \mathrm{NH}_{4} \mathrm{Cl}$ or $0.5 \%$ of each amino acid (presented using the three letter code). Presence $(+)$ or absence (-) of growth after $72 \mathrm{~h}$ (nitrogen-free medium) or $24 \mathrm{~h}$ (supplemented nitrogen-free medium or LB medium).

nd, not determined.

Table 2. B. vietnamiensis strains used in this study, and their acetylene reduction activity (ARA).

\begin{tabular}{|c|c|c|c|c|c|}
\hline Strains names & Origin & Species & nifH PCR & ARA & nifH probing \\
\hline 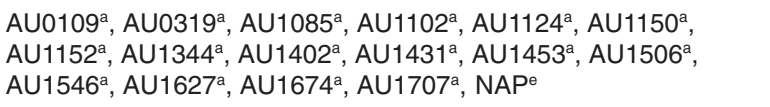 & CF patient & B. vietnamiensis & nd & + & nd \\
\hline 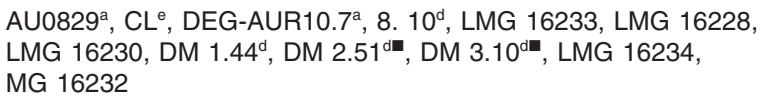 & CF patient & B. vietnamiensis & + & + & + \\
\hline LMG 6998, LMG 6999 & Blood, abscess & B. vietnamiensis & nd & + & nd \\
\hline 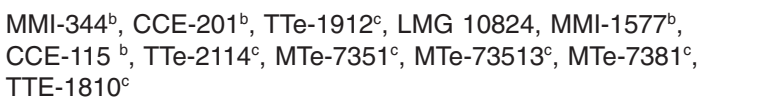 & Soil, rhizosphere & B. vietnamiensis & nd & + & nd \\
\hline 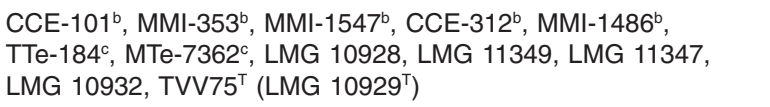 & Soil, rhizosphere & B. vietnamiensis & + & + & + \\
\hline CCE-21 ${ }^{\mathrm{b}}, \mathrm{CCE}-303^{\mathrm{b}}, \mathrm{TTe}-1812^{\mathrm{c}}, \mathrm{LMG} 10823$ & Soil, rhizosphere & B. vietnamiensis & + & + & nd \\
\hline ATCC 29424, ATCC 53617(G4) & Soil, waste water & B. vietnamiensis & + & + & + \\
\hline $\begin{array}{l}\text { AU0749a }{ }^{\mathrm{a}} \text { AU0913 }{ }^{\mathrm{a}}, \mathrm{AU} 1160^{\mathrm{a}} \\
\mathrm{JC} 2.10^{\mathrm{d}} \\
\mathrm{JC} 4.18^{\mathrm{d}} \\
\mathrm{CH}-\mathrm{D}^{\mathrm{e}}\end{array}$ & $\begin{array}{l}\text { CF patient } \\
\text { CF patient } \\
\text { CF patient } \\
\text { CF patient }\end{array}$ & $\begin{array}{l}\text { B. vietnamiensis } \\
\text { B. vietnamiensis } \\
\text { B. vietnamiensis } \\
\text { B. vietnamiensis }\end{array}$ & $\begin{array}{l}+ \\
+ \\
+ \\
-\end{array}$ & $\begin{array}{l}- \\
- \\
- \\
-\end{array}$ & $\begin{array}{l}+ \\
+ \\
+ \\
-\end{array}$ \\
\hline AU1458 ${ }^{\mathrm{a}}, \mathrm{JC} 7.79^{\mathrm{d} \bullet}$ & CF patient & B. multivorans & - & - & - \\
\hline ATCC 17616 & Polluted soil & B. multivorans & - & - & - \\
\hline ATCC 17759 & Soil & B. cepacia & - & - & - \\
\hline DM $4.20^{\mathrm{d}}$ & CF patient & B. stabilis & - & - & - \\
\hline
\end{tabular}

Results of the nifH DNA probings and PCR screenings are indicated.

Strains were from:

a. Burkholderia cepacia Research Laboratory and Repository at the University of Michigan.

b. Estrada-de Los Santos and colleagues (2001).

c. J. Caballero-Mellado collection.

d. French Observatoire cepacia.

e. E.Mahenthiraligam collection.

Strains coming from a same patient are indicated by black circles and squares. Strain JC 7.79 (black circle) was obtained after lung transplantation. Species determination was performed according to Mahenthiralingam and colleagues (2002). nifH PCR, ARA and nifH probings were as described in Experimental procedures. Strains with the same pattern are grouped. ARA- strains are boxed. nd, not determined.

C 2007 The Authors

Journal compilation @ 2007 Society for Applied Microbiology and Blackwell Publishing Ltd, Environmental Microbiology, 9, 1176-1185 
a

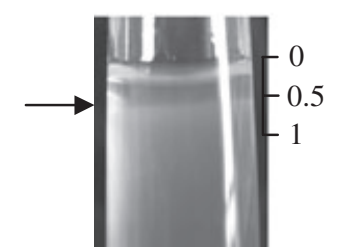

b

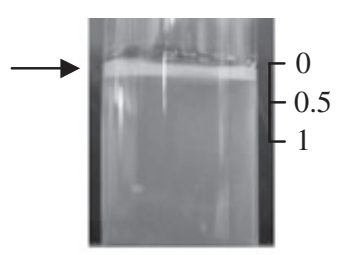

c

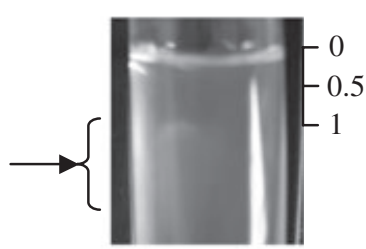

Fig. 3. Growth patterns of $B$. vietnamiensis strains in nitrogen-free semisolid medium.

A. > 2 mm depth growing strains, AU0319, AU1085, AU1102, AU1124, AU1152, AU1402, AU1453, AU1674, MMI-353, MMI-1486, MMI-344, MTe-7351, MTe-73513, MTe-7362, ATCC 29424, NAP, LMG 16230, DM 2.51, DM 3.10, LMG 16234.

B. Subsurface growing strains, AU1150, AU1344, AU1431, AU1506, AU1627, AU1707, CCE-101, MMI-1547, CCE-201, CCE-211, CCE-303, CCE-312, TTe-184, TTe- 1810, TTe-2114, LMG 10929, CL, DEG-AUR10.7, 8.10, LMG 6998, LMG 6999, LMG 10823, LMG 10824, LMG 16228, LMG 16232, LMG 11349, LMG 11347, LMG 10932, LMG 10928.

C. Delayed diffuse growth: AU0109, AU0829, AU1546, ATCC 53617, DM 1.44, LMG 16233. The following strains showed no growth, CH-D, AU0749, AU0913, AU1160, JC 2.10, JC 4.18. Scale is indicated in $\mathrm{cm}$.

strains growing in this semisolid nitrogen-free medium were shown to express the nitrogenase complex by the ARA assay (Table 2). Six strains (AU0749, AU0913, AU1160, JC 2.10, JC 4.18 and $\mathrm{CH}-\mathrm{D}$ ) recovered from CF patients were unable to fix nitrogen (Table 2). The proportion of nitrogen fixers among $\mathrm{CF}$ and environmental strains was found significantly different $(P<0.05)$. Growth differences in the semisolid nitrogen-free medium are likely due to differences in protection of the nitrogenase complex against oxygen. A nifH PCR was used to verify the presence of the nif cluster among most of these strains (Table 2). All strains tested that were growing under nitrogen-free conditions were found to harbour a nifH sequence. A single strain, $B$. vietnamiensis $\mathrm{CH}-\mathrm{D}$, out of the six that were unable to grow under nitrogen-free conditions, did not yield a nifH gene PCR product. This datum was further confirmed by nifH DNA probing of a B. vietnamiensis $\mathrm{CH}-\mathrm{D}$ DNA blot (Table 2; Fig. 4).

The six B. vietnamiensis strains showing no growth onto semisolid nitrogen-free medium were supplemented with various nitrogen sources such as $\mathrm{NH}_{4} \mathrm{Cl}$ and amino acids (Table 1). These supplements were defined according to Barth and Pitt (1995) who previously observed auxotrophies among a collection of Bcc strains from undefined species. These tests allowed to identify two natural nitrogen-fixing deficient ( $C H-D$ and AU0913) mutants which could grow on any of the nitrogenous supplements used. These strains had a behaviour very similar to the ones of the nif mutants produced by the genetic marker exchange experiments described in the previous section (Table 1). These strains were considered natural nif mutants because all enzymatic transformations of $\mathrm{NH}_{4} \mathrm{Cl}$ into amino acids appeared possible. The other four natural nitrogen-fixing deficient mutants were found to grow with supplements of specific amino acids suggesting mutations in amino acids biosynthesis or transformation pathways. One strain, JC 4.18, was found to require a tyrosine supplement, two strains,
AU0749 and AU1160, methionine supplements, and strain JC 2.10, to require a combination of amino acids i.e. serine with glutamate or glutamine or aspartate (Table 1).
nifH probing
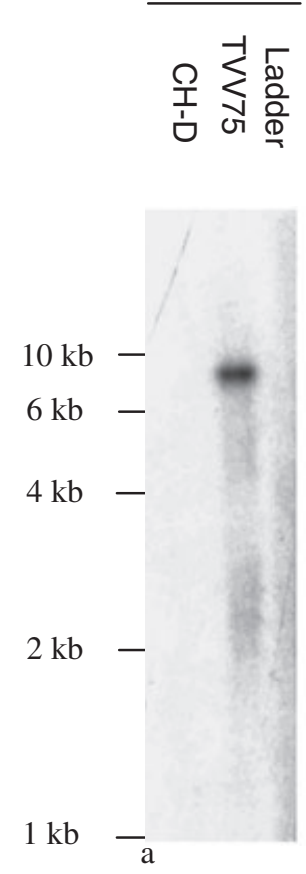

\section{nif cluster probing}
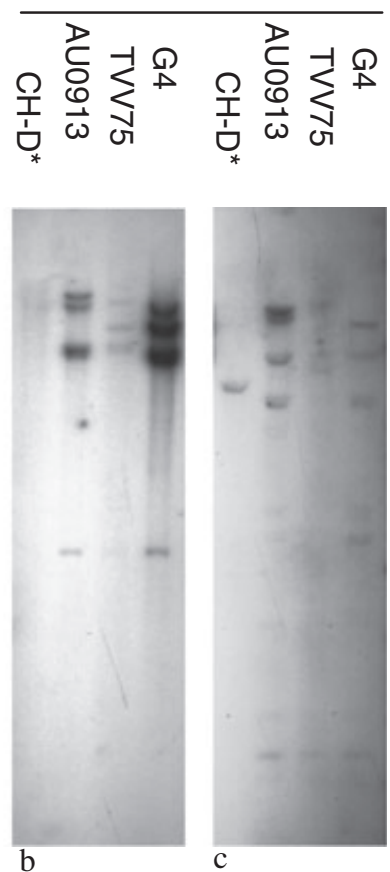

Fig. 4. nif probings of restricted $B$. vietnamiensis total DNA blots. DNA probings were performed as described in Experimental procedures. After agarose gel electrophoresis, restricted DNAs were transferred onto nylon membranes and hybridized with $(A)$ ${ }^{32} \mathrm{P}$-labelled nifH or (B and $\mathrm{C}$ ) the L3E pCPP47 ${ }^{32} \mathrm{P}$-labelled cosmid clone containing about $80 \%$ of the nif cluster of $B$. vietnamiensis strain TVV75 (see Fig. 1). *These hybridization patterns were the same as those obtained with ${ }^{32} \mathrm{P}$-labelled pCPP47 without an insert. A, EcoRI-, B, Bglll-, C, Clal-restricted total DNAs. Position of some DNA fragments of the Smart Ladder is indicated. 
In order to gain insights about the genetic disorders that could have played a role in the emergence of $B$. vietnamiensis nif mutants, DNA probings using the L3E cosmid (encoding about $80 \%$ of the nif cluster, see Fig. 1) were performed on restricted genomic DNA blots of these strains. The hybridization profiles (Fig. 4) confirmed loss of the nif cluster by the $B$. vietnamiensis $\mathrm{CH}-\mathrm{D}$ strain, and showed strain AU0913 to have a nif cluster similar to the one of strain G4, with little band variations. The loss of nitrogen-fixation activity by $B$. vietnamiensis AU0913 thus remains unexplained. In the previous section, lateral transfers of nifH genes were suggested to might have occurred between certain Burkholderia species. The origin of the nif clusters among $B$. vietnamiensis was thus verified. nifH sequences were obtained for a selection of $B$. vietnamiensis strains and introduced in the Burkholderia nifH data set built during this work. Phylogenetic analysis showed all $B$. vietnamiensis nifH sequences to be part of a single phyletic cluster and to show very few nucleotide changes (at least $99 \%$ identity). This analysis was in line with the recA PCR-RFLP identification of the strains used in this work. However, the fact that B. vietnamiensis $\mathrm{CH}-\mathrm{D}$ did not harbour any part of the nif cluster led us to further investigate its taxonomic status by DNA sequencing of its recA gene sequence. Phylogenetic analysis of this sequence confirmed the recA PCR RFLP analysis, and clearly clustered this sequence with recA sequences from well-established $B$. vietnamiensis strains, including the type strain (data not shown).

\section{Concluding remarks}

Nitrogen fixation is a complex process requiring several genes either directly involved in the synthesis of the dinitrogenase complex, its regulation or the transformation of fixed nitrogen into various essential nitrogenous molecules. NifA-, NtrB- and GInB-driven regulatory processes are likely playing a key role in the expression of $B$. vietnamiensis nif gene cluster. This cluster could be delimited, in this work, by the use of comparative genomics approaches, and was found to be made of about $40 \mathrm{~kb}$. Our data suggest that the CF lung environment can favour the loss of this genetic cluster. Other genetic disorders affecting $B$. vietnamiensis $\mathrm{N}_{2}$-fixing ability also appeared to be selected by the CF lungs. The high amino acids content of these lungs could be the physiological parameter leading to the emergence of these genetic rearrangements, and observed $B$. vietnamiensis variants. Sputum amino acid content of CF patients was found to be high during infective exacerbations and to correlate with pulmonary disease severity (Thomas et al., 2000). This parameter was previously found to increase the proportion of auxotrophs to prototrophs during infective exacerbation (Taylor et al., 1993). Here, two out of six
B. vietnamiensis nitrogen-fixing deficient strains, with distinct Spel PFGE profiles, came from a same patient, and could be supplemented with tyrosine, or a mixture of two amino acids. These data suggest that at the time these strains were collected, the patient could had been undergoing infective exacerbation that would have selected these variants. This would need to be further investigated. Interestingly, $\mathrm{N}_{2}$-fixing deficient strains recovered in this work came from three independent cohorts, suggesting that CF lungs could repeatedly lead to the emergence of such variants. Overall, these results and observations tend to suggest that CF lungs can favour the selection of genetic variants among community-acquired $B$. vietnamiensis, and that some of these variants will likely be affected in their nitrogen-fixing ability. These variants appear physiologically more dependent upon their CF host than their mother strain, and are unlikely to be highly competitive in the rhizosphere of most plants.

One of our future lines of research regarding this work will be to investigate the mechanisms involved in the emergence of these 'natural' nitrogen-fixing deficient strains selected by CF patients. IS elements could have played a role in their emergence. In fact, an IS element, IS402, was found physically close to B. vietnamiensis G4 nif cluster, and could have been the site for genetic recombination events that led to nif deletions.

\section{Experimental procedures}

Burkholderia vietnamiensis strains used and the $A R A$ assay

Burkholderia vietnamiensis strains used in this study are presented in Table 2. Burkholderia cepacia, B. multivorans and $B$. stabilis strains were used as negative controls throughout this work (Table 2). These strains were grown at $30^{\circ} \mathrm{C}$ on Luria-Bertani's Broth (LB) (Bertani, 1951) or LB containing $1.6 \%$ agar (LA). The taxonomic affiliation of these strains was confirmed by recA PCR-RFLP analyses (Mahenthiralingam et al., 2002). A Spel PFGE analysis of the genomic content of the $B$. vietnamiensis strains was performed according to Romling and colleagues (1997). Pulsed field gel electrophoreses were run for $11 \mathrm{~h}$ with a pulsed field of 5-25 s, followed by pulses of 5-60 s for $13 \mathrm{~h}$. Voltage was kept at $5 \mathrm{~V} \mathrm{~cm}^{-1}$. PFGE profiles were compared using the Gel compare software (Applied Maths). This analysis prevented over-representation of certain genotypes in the $B$. vietnamiensis strains panel of this study. The ARA assay was performed as described by Estrada de los Santos and colleagues (2001). The nitrogen-free medium used was slightly modified by replacing azealic acid by malic acid, and by not including bromothymol blue; the $\mathrm{pH}$ was adjusted to 6.5 . Inoculation of this medium was performed with late log phase growing cells in LB, washed twice with $0.8 \% \mathrm{NaCl}$. Statistical comparison of the proportion of nitrogen-fixing strains in our collection of CF and environmental strains was performed using the $Z$-test $(P<0.05)$ (Wassertheil-Smoller, 1995). 


\section{DNA manipulations}

PCR amplifications $(25 \mu \mathrm{l})$ were done according to the Taq polymerase manufacturer (Invitrogen, Cergy Pontoise, France) with $1.25 \mu \mathrm{l}$ of DMSO. $2.5 \mu \mathrm{l}$ of stationary phase cells was incubated for $10 \mathrm{~min}$ at $95^{\circ} \mathrm{C}$ and used directly in the $\mathrm{PCR}$ as the source of DNA matrices. nifH PCR primers were as follow: NifH1: GGCAARTCSACCACGTCG; NifH2: TGCTGNACGTGTTGTCGC. recA PCR primers are presented in Mahenthiralingam and colleagues (2002). PCR cycles were as follow: (i) $95^{\circ} \mathrm{C}$ for $5 \mathrm{~min}$, (ii) $95^{\circ} \mathrm{C}$ for $45 \mathrm{~s}$, $57^{\circ} \mathrm{C}$ for $45 \mathrm{~s}, 72^{\circ} \mathrm{C}$ for $45 \mathrm{~s}$ ( 35 cycles), (iii) $72^{\circ} \mathrm{C}$ for $5 \mathrm{~min}$. PCR products were sequenced by Genome Express (Meylan, France).

For DNA blot analyses, genomic DNAs were extracted according to Pitcher and colleagues (1989) and resuspended in $300 \mu \mathrm{l}$ of water. These DNAs $(5 \mu \mathrm{g})$ were digested by

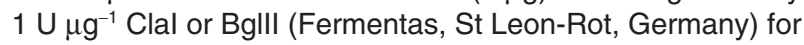
$16 \mathrm{~h}$ at $37^{\circ} \mathrm{C}$. DNA blots were performed using Genescreen Plus (PerkinElmer Life Science, Boston, USA) nylon membranes and the procedure described by Sambrook and colleagues (1989). nifH PCR products and L3E cosmid were labelled using the random priming labelling kit (AmershamPharmacia, Orsay, France). DNA hybridizations and nylon membrane washes were carried out according to the membrane manufacturer. Membranes were hybridized and washed at $65^{\circ} \mathrm{C}$. Autoradiography was performed according to Sambrook and colleagues (1989).

\section{Transposon mutagenesis}

Burkholderia vietnamiensis mutagenesis of TVV75 was performed using a transposome conferring resistance to kanamycin (Epicentre, UK) and introduced by electroporation. Electrocompetent $B$. vietnamiensis cells were obtained as follow: $250 \mathrm{ml}$ of LB broths of late-exponential phase growing cells was centrifuged for $15 \mathrm{~min}$ at $2600 \mathrm{RCF}$ and subsequently washed three times with $30 \mathrm{ml}$ ice cold $0.5 \mathrm{M}$ sucrose. Cells were resuspended in $100 \mu \mathrm{l} 0.5 \mathrm{M}$ sucrose and kept on ice until use. Electroporation was performed using the Bio-Rad Gene Pulser II set at $50 \mu \mathrm{F}, 800 \Omega, 2.5 \mathrm{kV}$ $1 \mu \mathrm{l}$ of transposome was mixed with $100 \mu \mathrm{l}$ of electrocompetent cells. These preparations were then introduced into cold $0.2 \mathrm{~cm}$ electroporation cuvettes and were electroporated. After electroporation, cells were incubated $1 \mathrm{~h}$ in LB broth, at $37^{\circ} \mathrm{C}$, and were then plated on LA containing $200 \mu \mathrm{g} \mathrm{ml}^{-1}$ kanamycin. Transposon rescue was performed according to

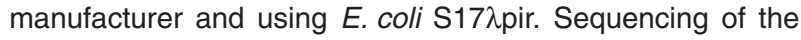
rescued plasmid was performed by Genome Express (Meylan, France).

\section{Genetic marker exchange}

Burkholderia vietnamiensis LMG 6998, LMG 10823 and CL were electroporated with plasmid pAM20 encoding part of the nif cluster and harbouring a $T n 7$ insertion in nifD. Transformants were plated on LA supplemented with $100 \mu \mathrm{g} \mathrm{ml}^{-1}$ of kanamycin, and incubated 2 days at $30^{\circ} \mathrm{C}$. Growing bacterial colonies were tested for nitrogen fixation (ARA assay) to verify inactivation of the targeted nif gene. Plasmid pAM20 was obtained as follow: a $B$. vietnamiensis TVV75 genomic
DNA library was built using the pCPP47 cosmid vector (Bauer and Collmer, 1997) in E. coli XL1 Blue MR. Among the gene library, a nif harbouring cosmid clone, named pAM18, was detected by nifH gene PCR amplification. pAM18 insertional mutagenesis was performed using the GPS system (Biolabs, Ozyme, Saint Quentin en Yvelines, France). pAM18 insertional mutants were electroporated into E. coli 10G Elite (from Lucigen) and plated on LA supplemented with $50 \mu \mathrm{g} \mu^{-1}$ kanamycin. Two hundred clones were retrieved. Pools of 12 clones were grown in LB supplemented with $50 \mu \mathrm{g} \mathrm{ll}^{-1}$ kanamycin, and their plasmid content was extracted and digested with Scal. Pools showing a band shift from pAM18 were further investigated. Individual cosmid clones from each positive pool were extracted, digested with Scal, analysed by electrophoresis, and transferred onto nylon membranes. nifH and GPS radioactive probes (labelled with Fermentas HexaLabel DNA labelling kit) were hybridized on these cosmid blots. Cosmid clones showing hybridization signals of the same size were sequenced using a GPS Tn primer. pAM19 showed a GPS Tn insertion in nifD. pAM19 was digested with Scal and the $6 \mathrm{~kb}$ fragment containing nifD-GPS was subcloned into the EcoRV site of pBluescript SKII (Invitrogen, Cergy Pontoise, France), leading to pAM20. pAM20 was analysed by EcoRI/HindIII digestions because the GPS Tn contains a unique HindIII site.

\section{Molecular phylogenetic analyses}

DNA sequences obtained in this work ( $n$ ifH) or from GenBank (nifH and rrs) were aligned using CLUSTALW (Thompson et al., 1994). Evolutionary distances between sequence pairs, the inferred phylogenetic trees, and bootstrap values were all computed through the Mega3 graphic tool (Kumar et al., 2004). Phylogenetic trees were built using the NeighbourJoining method (Saitou and Nei, 1987). Bootstrap replicates were performed using 1000 replicates. Gap containing sites were not included in the analyses.

The syntheny analysis was performed using the Artemis Comparison Tool (Carver et al., 2005), configured with TBLASTX input files (executable retrieved from the NCBI web site). Default per cent identity cut-offs were kept.

\section{Acknowledgement}

We thank E. Mahenthiralingam for having made available some CF B. vietnamiensis isolates from his collection.

\section{References}

Bani, D., Berberio, C., Bazzicalupo, M., Favilli, F., Gallori, E., and Polsinelli, M. (1980) Isolation and characterization of glutamate synthase mutants of Azospirillum brasilense. $J$ Gen Microbiol 119: 239-244.

Barth, A.L., and Pitt, T.L. (1995) Auxotrophy of Burkholderia (Pseudomonas) cepacia from cystic fibrosis patients. J Clin Microbiol 33: 2192-2194.

Barth, A.L., and Pitt, T.L. (1996) The high amino-acid content of sputum from cystic fibrosis patients promotes growth of auxotrophic Pseudomonas aeruginosa. J Med Microbiol 45: 110-119. 
Bauer, D.W., and Collmer, A. (1997) Molecular cloning, characterization, and mutagenesis of a pel gene from Pseudomonas syringae pv. lachyrmans encoding a member of the Erwinia chrysanthemi pelADE family of pectate lyases. Mol Plant Microbe Interact 10: 369-379.

Bauernfeind, A., Schneider, I., Jungwirth, R., and Roller, C. (1998) Discrimination of Burkholderia gladioli from other Burkholderia species detectable in cystic fibrosis patients by PCR. J Clin Microbiol 36: 2748-2751.

Bertani, G. (1951) Studies on lysogenesis. I. The mode of phage liberation by lysogenic Escherichia coli. $J$ Bacteriol 62: 293-300.

Bevivino, A., Tabacchioni, S., Chiarini, L., Carusi, M.V., Del Gallo, M., and Visca, P. (1994) Phenotypic comparison between rhizosphere and clinical isolates of Burkholderia cepacia. Microbiology 140: 1069-1077.

von Bredow, C., Birrer, P., and Griese, M. (2001) Surfactant protein $A$ and other bronchoalveolar lavage fluid proteins are altered in cystic fibrosis. Eur Respir J 17: 716-722.

Brygoo, E.R. (1953) [Natural agglutinins to Whitmore bacillus; specific agglutinins in various cases of melioidosis.]. Bull Soc Pathol Exot 46: 347-353.

Carver, T.J., Rutherford, K.M., Berriman, M., Rajandream, M.A., Barrell, B.G., and Parkhill, J. (2005) ACT: the Artemis comparison tool. Bioinformatics 21: 3422-3423.

Dixon, R., and Kahn, D. (2004) Genetic regulation of biological nitrogen fixation. Nat Rev Microbiol 2: 621-631.

Estrada de los Santos, P., Bustillos-Cristales, R., and Caballero-Mellado, J. (2001) Burkholderia, a genus rich in plant-associated nitrogen fixers with wide environmental and geographic distribution. Appl Environ Microbiol 67: 2790-2798.

Gillis, M., Van Van, T., Bardin, R., Goor, M., Hebbar, P., Willems, A., et al. (1995) Polyphasic taxonomy in the genus Burkholderia leading to an emended description of the genus and proposition of Burkholderia vietnamiensis sp. nov. for N2-fixing isolates from rice in Vietnam. Int $J$ Syst Bacteriol 45: 274-289.

Kumar, S., Tamura, K., and Nei, M. (2004) MEGA3: integrated software for molecular evolutionary genetics analysis and sequence alignment. Brief Bioinform 5: 150-163.

LiPuma, J.J. (2005) Update on the Burkholderia cepacia complex. Curr Opin Pulm Med 11: 528-533.

Magalhães, M., Doherty, C., Govan, J.R., and Vandamme, P. (2003) Polyclonal outbreak of Burkholderia cepacia complex bacteraemia in haemodialysis patients. J Hosp Infect 54: 120-123.

Mahenthiralingam, E., Baldwin, A., and Vandamme, P. (2002) Burkholderia cepacia complex infection in patients with cystic fibrosis. J Med Microbiol 51: 533-538.
Mahenthiralingam, E., Urban, T.A., and Goldberg, J.B. (2005) The multifarious, multireplicon Burkholderia cepacia complex. Nat Rev Microbiol 3: 144-156.

Mandal, A.K., and Ghosh, S. (1993) Isolation of a glutamate synthase (GOGAT)-negative, pleiotropically $\mathrm{N}$ utilizationdefective mutant of Azospirillum brasilense: cloning and partial characterization of GOGAT structural gene. J Bacteriol 175: 8024-8029.

O'Carroll, M.R., Kidd, T.J., Coulter, C., Smith, H.V., Rose, B.R., Harbour, C., and Bell, S.C. (2003) Burkholderia pseudomallei: another emerging pathogen in cystic fibrosis. Thorax 58: 1087-1091.

Perin, L., Martinez-Aguilar, L., Paredes-Valdez, G., Baldani, J.I., Estrada-de Los Santos, P., Reis, V.M., and CaballeroMellado, J. (2006) Burkholderia silvatlantica sp. nov., a diazotrophic bacterium associated with sugar cane and maize. Int J Syst Evol Microbiol 56: 1931-1937.

Pitcher, D.G., Saunders, N.A., and Owen, R.J. (1989) Rapid extraction of bacterial genomic DNA with guanidium thiocyanate. Lett Appl Microbiol 8: 151-156.

Romling, U., Schmidt, K.D., and Tummler, B. (1997) Large genome rearrangements discovered by the detailed analysis of 21 Pseudomonas aeruginosa clone $\mathrm{C}$ isolates found in environment and disease habitats. J Mol Biol 271: 386-404.

Saitou, N., and Nei, M. (1987) The neighbor-joining method: a new method for reconstructing phylogenetic trees. Mol Biol Evol 4: 406-425.

Sambrook, J., Fritsch, E.F., and Maniatis, T. (1989) Molecular Cloning: A Laboratory Manual. Cold Spring Harbor, NY, USA: Cold Spring Harbor Laboratory Press.

Somers, E., Vanderleyden, J., and Srinivasan, M. (2004) Rhizosphere bacterial signalling: a love parade beneath our feet. Crit Rev Microbiol 30: 205-240.

Taylor, R.F., Hodson, M.E., and Pitt, T.L. (1993) Adult cystic fibrosis: association of acute pulmonary exacerbations and increasing severity of lung disease with auxotrophic mutants of Pseudomonas aeruginosa. Thorax 48: 10021005.

Thomas, S.R., Ray, A., Hodson, M.E., and Pitt, T.L. (2000) Increased sputum amino acid concentrations and auxotrophy of Pseudomonas aeruginosa in severe cystic fibrosis lung disease. Thorax 55: 795-797.

Thompson, J.D., Higgins, D.G., and Gibson, T.J. (1994) CLUSTAL W: improving the sensitivity of progressive multiple sequence alignment through sequence weighting, position-specific gap penalties and weight matrix choice. Nucleic Acids Res 22: 4673-4680.

Wassertheil-Smoller, S. (1995) Biostatistics and Epidemiology: A Primer for Health Professionals. New York, USA: Springer-Verlag. 